\title{
Mind the Gap: Perceptions of Passenger Aggression and Train Car Supervision in a Commuter Rail System
}

\author{
Nerea Marteache, Gisela Bichler, and Janet Enriquez \\ California State University, San Bernardino
}

\begin{abstract}
Negative perceptions about the safety of a commuter rail system can act as a barrier to using public transportation. When operational issues increase rider tension (i.e., crowding or worsening on-time performance), or the management capabilities of conductors and law enforcement personnel are called into question, an upsurge in passenger-on-passenger aggression may occur. In turn, riders concerned about their safety may retreat to personal vehicles or other forms of "less risky" transit, such as express buses. Modifying an interstitial estimation process, this study presents a new method of identifying where rider concerns about public safety concentrate. Using the commuter rail system of Los Angeles as a case study, specific inbound and outbound trip segments were found to exhibit different problems. Raw scores identify segments in need of greater train car supervision, and these segments differ from where discontented riders congregate (requiring customer service outreach). Tailored responses, focused on a few segments, stand to improve perceptions of safety and, ultimately, may increase ridership.
\end{abstract}

\section{Introduction}

The use of public transportation has widely-recognized benefits at many levels. Public transit reduces traffic congestion, which increases public interest in the provision of convenient and affordable mass transit services. This issue is of special concern in the Los Angeles metropolitan area, which was considered to have the worst commute in the United States in 2007 based on pollution levels, time spent in rush-hour traffic, and number of per-capita fatal car accidents (Forbes 2007). ${ }^{1}$ In 2011, the advocacy group Transportation for America ranked this region the second-worst in the country regarding the accessibility of public transit for older adults. ${ }^{2}$

\footnotetext{
${ }^{1}$ http://www.forbes.com/2007/07/23/health-commute-pollution-forbeslife-cx_avd_0724commute.html (accessed August 8, 2014).

${ }^{2}$ http://t4america.org/docs/SeniorsMobilityCrisis.pdf (accessed August 8, 2014).
} 
However, people take advantage of public transportation services only when systems run efficiently and are perceived to be safe. Studies in the U.S. and overseas (New York, Washington DC, London, Stockholm, etc.) have shown that transit crime affects all large systems, reducing the number of passengers, creating service disruptions and decreasing revenue (Clarke, Belanger and Eastman 1996; LaVigne 1996; Crime Concern 2002; Newton 2004; Ceccato 2013). Interestingly, the results of these studies show that crime does not happen evenly across the system; it concentrates on specific lines, segments, and stations.

Existing research on perceptions of safety in public transportation explores issues such as whether fear of crime is affected by experiences of victimization (Feltes 2003; Crime Concern 2002, 2004); which factors influence perceptions of safety when using public transportation (Currie, Delbosc, and Mahmoud 2013); and the use of social media to study those perceptions (Collins, Hasan, and Ukkusuri 2013). The questions of exactly where incidents that generate perceptions of unsafety occur, and in what parts of the system riders feel more fearful, remain unanswered.

Our study addresses these questions by employing a unique method, as described below, for estimating where and when public safety problems occur and where discontent accumulates among the ridership of the Los Angeles Commuter Rail system, Metrolink. We begin by considering the role place managers play in ensuring train car safety and the importance of pinpointing where incidents occur and concentrate in the system. This section is followed by a brief description of Metrolink. Then, we explain the estimation process and the results. To conclude, we discuss the implications of this work and offer a few suggestions about how to address public safety concerns.

\section{Transit Crime and Public Safety Issues}

Many criminologists argue that crime and public safety issues emerge when opportunity abounds. Illustrated in Figure 1, the conditions that generate opportunities can be reduced to six essential factors (Felson, 2006). Crime occurs when (1) a suitable target and (2) motivated offender encounter each other, (3) converging in time and space, in the absence of protective agents. Protective agents watching over the possible targets are called (4) capable guardians and those keeping an eye on possible offenders are described as (5) intimate handlers. By some accounts the most critical protective agent is the one monitoring the place where convergence occurs, these are (6) place managers. Place managers are critical to public safety as they have the authority to control behavior in their assigned area, either by proactively working to prevent crime or responding to issues as they unfold. Conductors are important place managers because they have access to resources. For instance, they can call for sheriff support and they can fine or eject riders that behave badly. Ejecting riders temporarily suspends their privilege to travel on the system, and this can act as an effective deterrent. However, as research demonstrates (e.g., LaVigne 1996; Ceccato 2013), motivated offenders must perceive that this response is a certain consequence of bad behavior and that conductors and their law enforcement counterparts will act with celerity. 
FIGURE 1. Routine Activities Theory

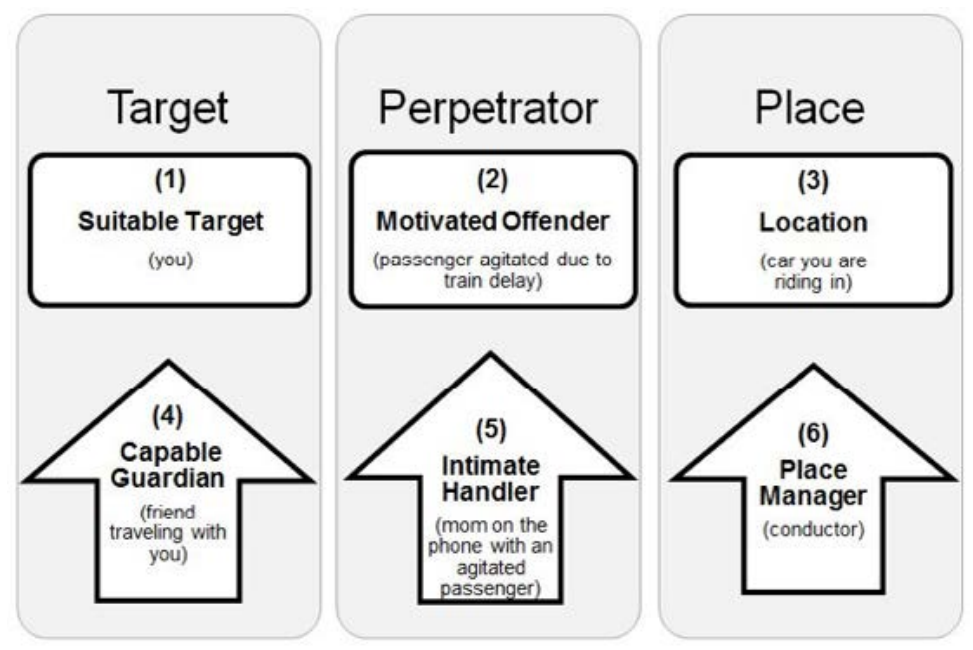

One of the challenges unique to transportation research is determining where an incident occurs during a journey. Reporting mechanisms generally record the train number, date, and time and, on rare occasions, the origin and destination stations of the parties involved; missing is the exact location of where an issue occurred. Moreover, since the train may be in motion when an issue transpires, it is not entirely certain how much of the trip is affected by the incident. This means that since people board at each station while the train is en route, an incident may continue with a new batch of riders-unsuspecting riders, not having witnessed the beginning of the incident, may be caught off-guard.

Fortunately, this problem of geographic imprecision received a great deal of attention, and an aoristic procedure was adopted to address it (e.g., Ashby and Bowers 2013; Newton 2004; Ratcliffe 2002). Applied to crime and public safety, aoristic techniques estimate the time at which incidents are likely to have occurred at specific locations. Recast as an "interstitial" estimation process (Newton, Partridge, and Gill 2014), with information about the line, time of day, origin, and destination, it is possible to calculate the probability that an event occurred at any point of the complainant's journey. By summing these probabilities for all reported incidents, it is possible to generate a sense of when and where events are likely to concentrate.

\section{Metrolink}

Metrolink ${ }^{3}$ is a regional commuter rail service operated by the Southern California Regional Rail Authority (SCRRA). It is the third-largest commuter rail agency in the United States based on its 512-mile directional route network and the seventh-largest based on annual ridership. Metrolink operates 7 lines across 6 counties and serves 55 stations, most of which are located in different cities. At various locations, the system connects with Amtrak, light rail, and bus services. Metrolink equipment includes 55 locomotives and 184 coaches with an average passenger capacity of 150 passengers and 90 cab cars with a capacity of approximately 101-130 passengers. Although Metrolink operates throughout a region that contains close to 20 million people, it recorded an average weekday rider-

${ }^{3} \mathrm{~A}$ map of the system is available at http://www.metrolinktrains.com/pdfs/MetrolinkMap.pdf. 
ship of only 40,795 boardings during the second quarter of FY 2013-2014. Passenger trips average 38 miles, and 65\% of riders commute to/from work (Metrolink 2014).

Trains are staffed with a conductor and an engineer subcontracted from Amtrak, who are supervised by Metrolink compliance officers. If a public safety issue arises at any point in the journey or on a platform, the responsible agency is the L.A. County Sheriff's Department. Issues occurring at a station or in a parking facility fall under the domain of the City's contracted private security or law enforcement agency, as each city maintains its own stations. Sometimes Metrolink security officers and Customer Engagement Representatives (CERs) are deployed to stations to ensure safe boarding of trains during peak ridership or to assist with service disruptions and bus bridges.

\section{Goals of the Current Study}

With such a large service area, ensuring effective place management along all routes is a significant operational challenge for Metrolink. The goal of this study was to identify the segments (portions of the train line between stations) that pose the greatest perceived public safety risk.

Not everyone voices their opinions, and reporting systems rarely capture all information necessary for problem identification and diagnosis. For instance, estimates suggest that, at the most, 1 in 5 people and, at the least, 1 in 20 riders actually notify transit services of problems encountered while en route (Vavra 1997). Recordkeeping by conductors and law enforcement officers capture some concerns, but much activity goes unobserved. When information is available, complainants are often vague about where and when incidents occurred. Thus, with such a large gap in information, alternative methodologies are needed to estimate the concerns of riders.

When analyzing crime and public safety issues, it is important to consider both the volume of activity occurring at specific locations and the rate of occurrence based on the number of people accessing the system. Each calculation tells us something unique about the situation. Tabulating the volume of incidents occurring on each trip segment indicates where problems concentrate (raw scores). This is useful for knowing where to aim interventions for maximum impact. However, travel segments servicing a disproportionate level of worried passengers reveal parts of the system where the ridership feels more vulnerable. These complaint rates suggest where the customer service department and marketing team can focus outreach efforts to address safety concerns that, if resolved, may increase ridership. ${ }^{4}$ Figure 2 outlines the four research questions that drive this study.

\footnotetext{
${ }^{4}$ An example illustrates the need for both calculations. If we analyze two trip segments $(A \rightarrow B$ and $B \rightarrow C)$, we might see that in the first one there were 5 incidents and in the second one there were 20 incidents. The volume of problems would indicate that the second leg is more problematic. But if we account for ridership (10 people traveling the first leg and 400 traveling the second), we would find that concern about those incidents is much higher on the first segment $(A \rightarrow B)$, as it is being reported at much higher rates.
} 
FIGURE 2.

Research questions
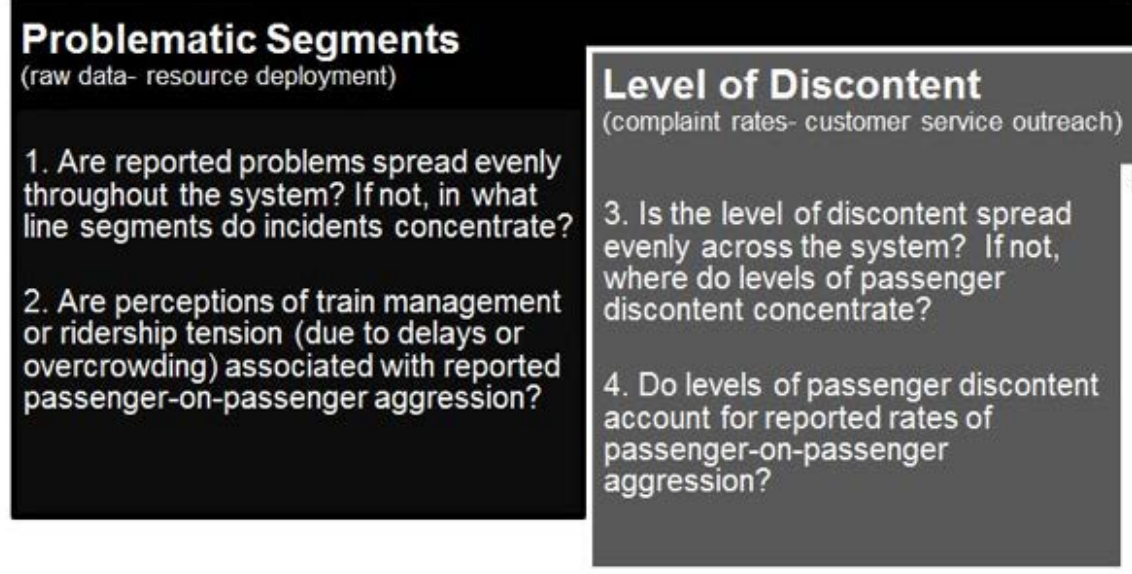

\section{Methods}

\section{Data}

Complaint information from August 1, 2009, to December 31, 2012, was extracted from an archive maintained by the Customer Engagement Department of Metrolink. Although many communication channels exist, this archive captures only formal correspondenceemail, letters, and phone calls. Each issue raised is recorded, and a single customer contact can include multiple complaints and/or commendations. As outlined in Table 1, four categories of complaints were used-Rider Tension (including On-Time Performance and Crowding complaints), perceptions of train car Supervision (which indicates perceived quality of place management), and Passenger-on-Passenger Aggression (dependent variable).

TABLE 1.

Description of Customer Complaints about Incidents Occurring while Onboard or during Boarding/Alighting

\begin{tabular}{|l|l|c|c|c|}
\hline \multicolumn{1}{|c|}{ Category } & \multicolumn{1}{|c|}{ Description } & $\begin{array}{c}\text { Total } \\
\text { Issues }\end{array}$ & $\begin{array}{c}\text { Included } \\
\text { in Study }\end{array}$ & \% Lost \\
\hline $\begin{array}{l}\text { Rider Tension: } \\
\text { On-Time } \\
\text { Performance } \\
\text { (OTP) }\end{array}$ & $\begin{array}{l}\text { Concerns about delays and disruptions to regular } \\
\text { service (excluding planned maintenance) }\end{array}$ & 1,574 & 1,423 & 9.6 \\
\hline $\begin{array}{l}\text { Rider Tension: } \\
\text { Crowding }\end{array}$ & $\begin{array}{l}\text { Statements about inability to find seating, and } \\
\text { congestion in vestibules and stairs (e.g., too many } \\
\text { bicycles or luggage blocking movement) }\end{array}$ & 99 & 82 & 17.2 \\
\hline Supervision & $\begin{array}{l}\text { Statements about a conductor or sheriff not } \\
\text { enforcing rules, behaving inappropriately, being } \\
\text { aggressive, or failing to respond to a request }\end{array}$ & 497 & 455 & 8.5 \\
\hline $\begin{array}{l}\text { Passenger- } \\
\text { on-Passenger } \\
\text { Aggression }\end{array}$ & $\begin{array}{l}\text { Victimization or witnessing aggressive behavior by a } \\
\text { passenger on another rider, including assaults, verbal } \\
\text { threats, defiance, and disorderly conduct }\end{array}$ & 192 & 163 & 15.1 \\
\hline
\end{tabular}

Note: Only formal complaints (email, letters, or phone) are included; tweets and Facebook posts are not. Cases were lost due to missing information about origin or destination of trip. 


\section{Interstitial Estimation Technique}

Interstitial estimation (Newton et al. 2014), as depicted in Figure 3, provides a method for determining where problems are likely to have occurred given where a person got on the train and at what station he/she departed. For example, a rider writes in to complain about an issue occurring during a trip (Trip 1). In this instance, the trip involves two segments (between stations), and we estimate that it is equally likely that the incident occurred during the first segment as the second. A value of 0.5 (probability) is assigned to each segment. A second incident is reported by someone boarding at station B and traveling to the end of the line. The likelihood that the incident occurred on any segment is $1 / 5$ segments or 0.2 . The third reported issue involved a person traveling three segments, and the probability of the incident occurring on any one segment is $1 / 3$ or 0.33 . By summing all probabilities for each segment, we arrive at a total estimated probability of issues occurring for each segment of a line. Separate estimates were generated for inbound (toward L.A. Union Station or Riverside Station) and outbound travel. These values are used to weight the transportation network.

FIGURE 3.

\section{Train Line}

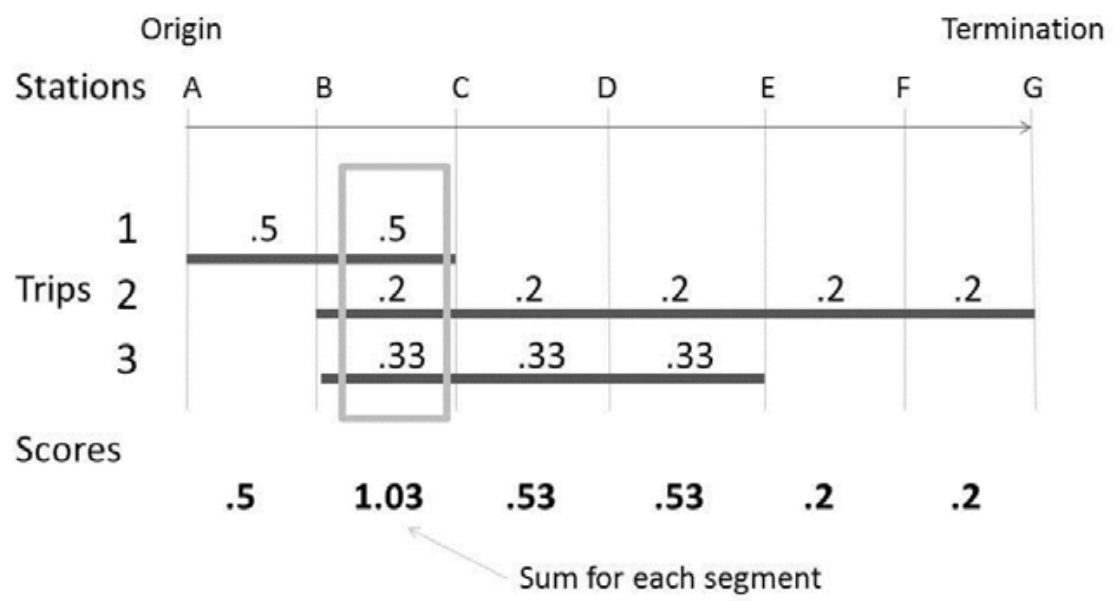

\section{Calculating Rates}

The process described above provides the estimated number of incidents (raw estimate) per segment. It does not take into consideration the number of passengers that typically ride the line. To convert the raw estimates into rates per 1,000 passengers, ${ }^{5}$ we divided the estimated probability of problems by the number of riders per segment. To calculate the number of riders on each segment, we used the number of boardings per station and the number of riders per line during peak travel. This process is outlined in Figures 4(a) and 4(b).

\footnotetext{
${ }^{5}$ Using the industry standard of 100,000 riders was not feasible given the low level of ridership.
} 
FIGURE 4(a).

Calculating percent of boardings for each station,

per line and by direction

traveled

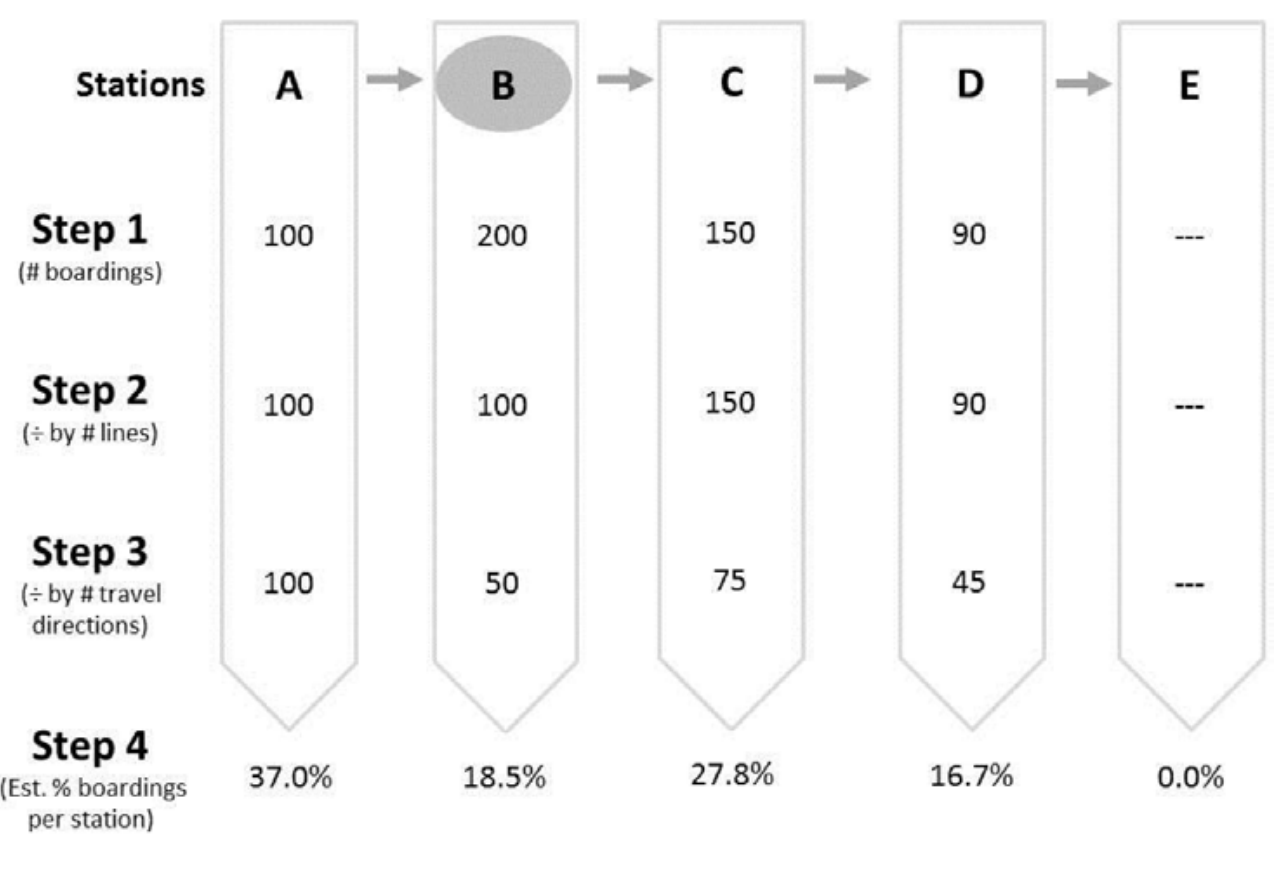

Station serviced by 2 lines (all other stations are serviced by 1 line only)

FIGURE 4(b).

Process used to estimate ridership, per trip segment
Line segments

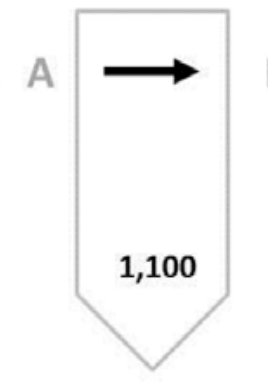

\section{Step 6}

(Add cumulatively towards end of line)
1,100

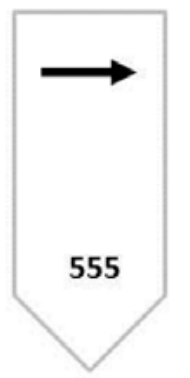

1,665

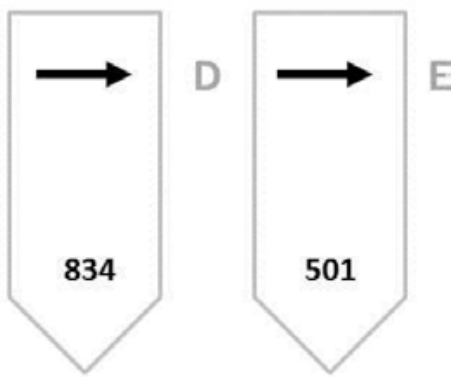

2,499

\footnotetext{
${ }^{*}$ In this example, the total number of riders per line is 3,000 passengers.
}

We began Step 1 with the total number of boardings at each station. This count of passengers entering the system was divided by the number of lines servicing the station (Step 2) and the number of travel directions of each line at each station (Step 3). This estimated the number of passengers entering each line in each of the travel directions (inbound or outbound). The end of line station was not included, as passengers would only be able to get off the train, not on it. The first part of the calculation resulted in the percent of boardings for each station (Step 4) per line and by direction traveled.

The second part of the calculation generated an estimate of ridership per trip segment. In Step 5 , the percent of boardings per station was applied to the total number of riders per 
line and direction traveled. Finally, the estimated ridership per segment was obtained by adding the number of riders cumulatively toward the end of the line (Step 6).

\section{Results}

Figure 5(a) illustrates the transit network as it reflects customer complaints. Thicker line widths indicate a greater probability of issues that generate complaints. Arrowheads indicate the travel direction. Recall that raw scores tell us where problem behavior is likely to occur (Figure 5[a]) and rates suggest where greater proportions of discontented riders concentrate (Figure 5[b]).

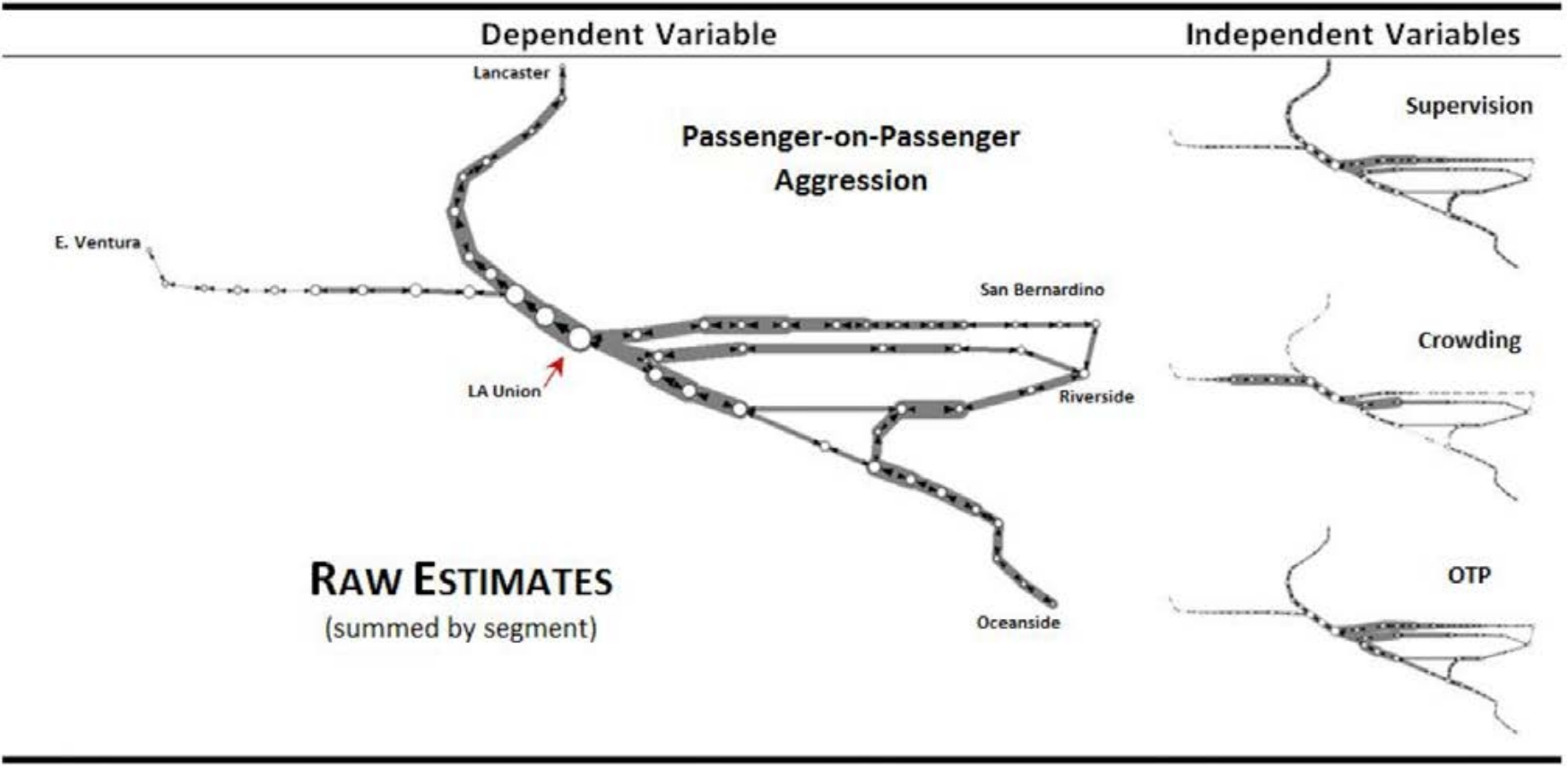

Note: Station symbols vary in size to reflect a statistic called betweenness centrality. Bigger symbols identify stations that are more central to the flow of passengers throughout the entire system (across differentlines).

FIGURE 5(a). Visualization of trip segment values for customer complaints, raw estimates

Figure 5(a) shows that reports of passenger-on-passenger aggression concentrate in and around the center of the system (LA Union Station), on the Antelope Valley line (Lancaster-LA Union Station), and the Inland Empire-Orange County line (San BernardinoOceanside). The center of the system and the segments close to it accumulate most of the complaints for OTP, crowding, and train car supervision.

Standardized values (Figure 5[b]) suggest that aggression disproportionately concerns riders mostly at the beginning of the Ventura County Line (East Ventura) and on the Inland Empire-Orange County line. These same segments display higher rates of complaints about train car supervision and crowding, while levels of discontent about on-time performance seem to affect the Riverside and 91 lines as well. The high volume of complaints in the center of the system displayed in Figure 5(a) does not correspond with a high level of concern among the passengers (Figure 5[b]), as it is also the part of the system where most riders concentrate. 


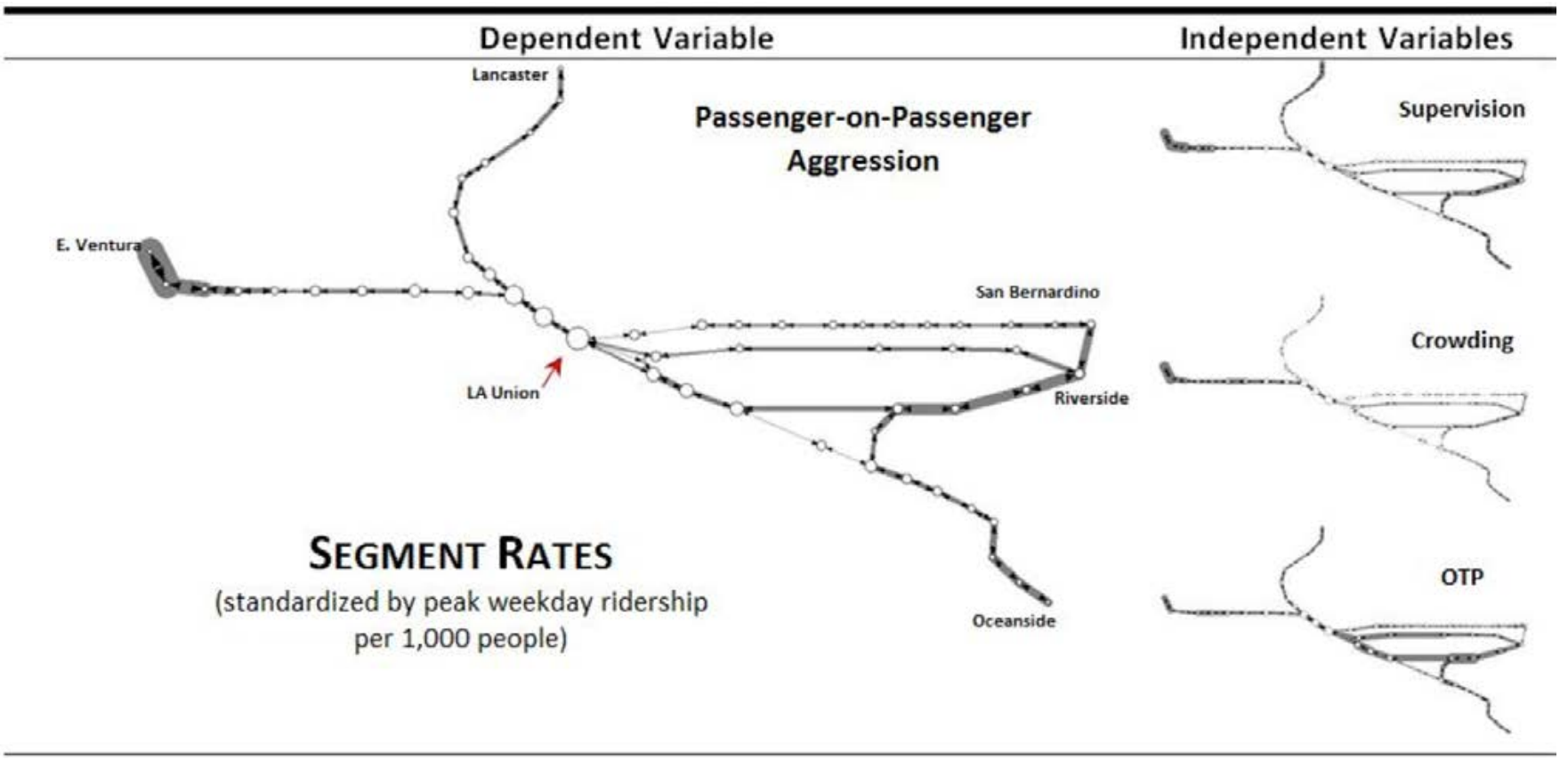

FIGURE 5(b). Visualization of trip segment values for customer complaints, segment rates

TABLE 2.

Correlations between Customer Complaint Categories by Trip Segments
The patterns suggested in Figure 5 are further detailed in Table 2. Spearman's Rho coefficients suggest that irrespective of the direction of travel, the prevalence of aggression complaints is correlated with OTP complaints and perceptions of poor train car supervision. However, when we are interested in finding out the segments with higher rates of aggression complaints, poor supervision is the primary correlate for inbound travel. Outbound, a greater proportion of riders who see public safety problems are comingling (or the same complainants may report several issues) with those perceiving crowdedness and problems with on-time-performance.

\begin{tabular}{|c|c|c|c|c|c|}
\hline \multirow{5}{*}{$\begin{array}{l}\text { Raw } \\
\text { Estimates }\end{array}$} & & $\begin{array}{l}\text { P-on-P } \\
\text { Aggression }\end{array}$ & $\begin{array}{l}\text { On-time } \\
\text { Performance }\end{array}$ & Crowded & Supervision \\
\hline & $\begin{array}{l}\text { Passenger-on-Passenger } \\
\text { Aggression }\end{array}$ & & $0.850^{\mathrm{a}}$ & 0.227 & $0.804^{\mathrm{a}}$ \\
\hline & On-time Performance & $0.778^{\mathrm{a}}$ & & $0.453^{\mathrm{a}}$ & $0.814^{\mathrm{a}}$ \\
\hline & Crowded & $0.338^{\mathrm{a}}$ & $0.413^{\mathrm{a}}$ & & 0.170 \\
\hline & Supervision & $0.753^{\mathrm{a}}$ & $0.783^{\mathrm{a}}$ & 0.172 & \\
\hline \multirow{4}{*}{$\begin{array}{l}\text { Rate per } \\
1,000 \\
\text { People }\end{array}$} & $\begin{array}{l}\text { Passenger-on-Passenger } \\
\text { Aggression }\end{array}$ & & $0.456^{\mathrm{a}}$ & $0.622^{\mathrm{a}}$ & $0.722^{\mathrm{a}}$ \\
\hline & On-time Performance & $0.794^{\mathrm{a}}$ & & $0.587^{\mathrm{a}}$ & $0.378^{\mathrm{a}}$ \\
\hline & Crowded & $0.773^{\mathrm{a}}$ & $0.551^{\mathrm{a}}$ & & $0.596^{a}$ \\
\hline & Supervision & $0.773^{\mathrm{a}}$ & $0.819^{\mathrm{a}}$ & $0.628^{a}$ & \\
\hline
\end{tabular}

Shaded cells indicate outbound travel, and white cells indicate inbound travel.

${ }^{a} \mathrm{p}<.001 ; \mathrm{N}=72$; the significance of these Spearman Rho's coefficients was established with a nonparametric bootstrapping procedure ( $n=1,000$ samples). 
Correlations tell only part of the story. Turning to the regression estimates reported in Table 3, it becomes clear that on-time performance is more than three times more important in predicting the number of passenger-on-passenger incidents of aggression (raw values) during inbound travel than all other factors. On the outbound journey, high numbers of reported passenger aggression can be accounted for by complaints about conductors and security (our measure of train car supervision).

\begin{tabular}{|c|c|c|c|c|c|c|}
\hline \multirow{12}{*}{$\begin{array}{r}\text { TABLE } 3 . \\
\text { Customer Complaint } \\
\text { Categories Regressed on } \\
\text { Passenger-on-Passenger } \\
\text { Aggression }\end{array}$} & & & \multicolumn{2}{|c|}{ Raw Estimates } & \multicolumn{2}{|c|}{ Rate per 1,000 People } \\
\hline & & & $\beta$ & Sig. & $\beta$ & Sig. \\
\hline & \multirow{5}{*}{$\begin{array}{l}\text { Inbound } \\
\text { Travel }\end{array}$} & On-time Performance & 0.724 & 0.000 & -0.066 & 0.310 \\
\hline & & Crowded & -0.112 & 0.072 & 0.355 & 0.000 \\
\hline & & Supervision & 0.218 & 0.051 & 0.647 & 0.000 \\
\hline & & $\mathrm{F}$ & $91.305^{a}$ & & $92.913^{\mathrm{a}}$ & \\
\hline & & Adjusted $\mathrm{R}^{2}$ & 0.792 & & 0.795 & \\
\hline & \multirow{5}{*}{$\begin{array}{l}\text { Outbound } \\
\text { Travel }\end{array}$} & On-time Performance & 0.068 & 0.744 & 0.279 & 0.000 \\
\hline & & Crowded & 0.295 & 0.002 & 0.792 & 0.000 \\
\hline & & Supervision & 0.570 & 0.006 & -0.011 & 0.859 \\
\hline & & $\mathrm{F}$ & $25.049^{\mathrm{a}}$ & & $302.558^{a}$ & \\
\hline & & Adjusted $\mathrm{R}^{2}$ & 0.504 & & 0.927 & \\
\hline
\end{tabular}

$\mathrm{N}=72$ trip segments; 1,000 bootstrap samples were used to test these effects and generate corresponding $95 \%$ confidence intervals (available upon request).

${ }^{\mathrm{a}} \mathrm{p}<0.001$.

Interestingly, the rate of passenger-on-passenger aggression exhibits opposite patterns. Greater concern about passenger aggression corresponds with complaints about inadequate supervision (inbound) and crowdedness (outbound). This means that, regardless of where the incidents actually accumulate, the proportion of passengers reporting on aggression is linked to concerns about supervision on the way to work and about crowded trains on the return journey. More research is needed to fully understand how crowd sentiment (the aggregated perceptions of passengers) interacts with fear of violence.

\section{Discussion}

The onboard climate is more than simply the temperature. Passengers expect not only a reliable, clean, and comfortable environment, but also a safe one. Experiencing or witnessing an altercation while riding on a train is an upsetting event that contaminates the onboard climate and affects passenger impressions of that specific trip, and of the system as a whole.

More than $60 \%$ of Metrolink riders commute to work. When traveling on a train, passengers find themselves in an enclosed setting. Over time, passengers commuting on a regular basis come to know, perhaps only by sight, the others with whom they typically travel. When passenger-on-passenger aggression occurs, the effects of the incident will linger among the crowd. Conflict builds. Declining OTP will increase anxiety and stress among passengers, which in turn, may generate more arguments among passengers. 
After a long day, a crowded train seems to have that same impact on riders. In both cases, concern about car management is associated with significantly higher levels of aggression. If a conductor is perceived to be unable to handle an issue, trust in the ability of Metrolink to maintain the rules and keep riders safe is called into question, because conductors are the most immediate place managers of train cars. This significantly affects the willingness of people to take public transportation (e.g., Newton 2004; Ceccato 2013).

Tailored responses, focused on asserting stronger train car management in a few problematic segments, stands to improve perceptions of safety and, ultimately, increase ridership. In this research, we looked at safety concerns from two perspectives:

- On one hand, identifying the segments with the higher volume of incidents shows where aggression is actually happening.

- In the short term, directing security personnel and law enforcement to the specific segments with higher volume of aggressions (which are mostly located in and around the center of the system) could reduce the total number of aggressive incidents happening in the system.

- Long term, the causes of those incidents must be identified and addressed.

- On the other hand, complaint rates show where passengers are most concerned about aggression, even if the total number of incidents in those locations is low. If a car is full of passengers, a small argument occurring on one end will have little effect on riders sitting 20 rows away. However, if the car is relatively empty, as is often the case toward the end of the line, the effects of one small fight between passengers is magnified. Fear and concern may escalate if help is not forthcoming from the conductor.

- In the short term, many strategies can be deployed to enhance relations between car managers (conductors) and riders. For example, conductors can be strategically placed to be visible and available at the end of line stations; placards can be posted and flyers distributed to inform passengers about who to call for safety concerns; special promotions distributed by conductors (e.g., giving away pins, special event trip tickets, or other materials) can be used to foster positive interactions with riders.

- Long term, it is advisable to implement a new approach to train car management on affected segments. Additionally, sustained outreach to disaffected riders through social media and other mechanisms may help to turn complainants into advocates who will attract other riders by sharing positive assessments of their public transit experience.

This is just the beginning of the analysis of this problem which, while providing a good understanding of the Metrolink system through passenger eyes (their complaints) raises new questions. Future research should include direct measures of incidents of aggression and of perceived safety, using crime data and passenger surveys, respectively. Agencies such as Metrolink should consider keeping track of alternative sources of information such as social media (Facebook, Twitter, YouTube, etc.) and building analytic capabilities 
of these data into their systems. This information could then be matched to more reliable sources of data.

Given the complexity of the system, other variables and units of analysis (stations) should be included in future analyses: measures of specific place management at each station, how many jurisdictions overlap at each segment, the number of systems coinciding at each point of the system (Amtrak, bus, subway), etc.

Light rail and bus service connections provide Metrolink passengers with many multimodal public transit service options, and this significantly increases the mobility of riders. Generally, these multimodal linkages also extend the impact that perceptions of safety and efficiency of Metrolink have on public transit systems. Reducing the number of problems and feelings of unsafety will very likely increase ridership across the whole system.

\section{References}

Ashby, M. P. H., and K. J. Bowers 2013. "A Comparison of Methods for Temporal Analysis of Aoristic Crime." Crime Science, 2 (1): 1-18.

Ceccato, V. 2013. Moving Safely. Crime and Perceived Safety in Stockholm's Subway Stations. Plymouth, U.K.: Lexington Books.

Clarke, R., M. Belanger, and J. Eastman. 1996. "Where Angel Fears to Tread: A Test in the New York City Subway of the Robbery/Density Hypothesis." In R. Clarke (ed.), Preventing Mass Transit Crime. Crime Prevention Studies. Vol. 6. Monsey, NY: Criminal Justice Press.

Collins, C., S. Hasan, and S. V. Ukkusuri. 2013. "A Novel Transit Rider Satisfaction Metric: Rider Sentiments Measured from Online Social Media Data." Journal of Public Transportation, 16 (2).

Crime Concern. 2002. "People Perceptions of Personal Security and Their Concerns about Crime on Public Transport: Literature Review." London, UK: Department for Transport.

Crime Concern. 2002. "People Perceptions of Personal Security and Their Concerns about Crime on Public Transport: Research Findings." London, UK: Department for Transport.

Currie, G., A. Delbosc, and S. Mahmoud. 2013. "Perceptions of Personal Safety on Public Transport." Journal of Public Transportation, 16 (1).

Feltes, Thomas. 2003. "Public Safety and Public Spaces: The Citizen's Fear of Strangers." In European Conference for Ministers of Transport: Economic Research Centre (eds.), Vandalism, Terrorism and Security in Urban Public Transport, Round Table 123.

LaVigne, N. 1996. "Safe Transport: Security and Design on the Washington Metro." In R. Clarke (ed.), Preventing Mass Transit Crime. Crime Prevention Studies. Vol. 6. Monsey, NY: Criminal Justice Press. 
Metrolink. 2014. Metrolink Fact Sheet for Q2 (2014). http://www.metrolinktrains.com/ pdfs/Facts\&Numbers/Fact_Sheets/Fact_Sheet_2014_Q2.pdf, accessed October 3, 2014.

Newton, A. D. 2004. “Crime on Public Transport: 'Static' and 'Non-Static' (Moving) Crime Events." Western Criminology Review, 5 (3): 25-42.

Newton, A. D., H. Partridge, and A. Gill. 2014. "Above and Below: Measuring Crime Risk in and around Underground Mass Transit Systems." Crime Science, 3 (1): 1-14.

Ratcliffe, J. H. 2002. "Aoristic Signatures and the Spatio-Temporal Analysis of High Volume Crime Patterns." Journal of Quantitative Criminology, 18 (1), 23-43.

Vavra, T. G. 1997. Improving Your Measurement of Customer Satisfaction: A Guide to Creating, Conducting, Analyzing, and Reporting Customer Satisfaction Measurement Programs. Milwaukee, WI: ASQ Quality Press.

\section{About the Authors}

Dr. Nerea MARTEAChe (nmarte@csusb.edu) received a Ph.D. from Rutgers University in 2013 and is an Assistant Professor of Criminal Justice at California State University, San Bernardino. Her scholarship focuses on crime prevention through opportunity reduction, and on the analysis and evaluation of criminal justice policy. Her current research examines the opportunity structure of crimes committed by employees, crime and disorder in mass transit systems, and wildlife crime. Recent publications have appeared in the European Journal of Criminology, Proceedings of Criminology, and Revista Española de Investigación Criminológica.

Dr. Gisela BichleR (gbichler@csusb.edu) received a Ph.D. from Rutgers University in 2000 and is a Professor of Criminal Justice at California State University, San Bernardino and Director of the Center for Criminal Justice Research (CCJR). As the CCJR Director, she works with a range of criminal justice agencies, community groups, and city governments to develop solutions to local crime and public safety issues that invoke stronger place management and situational crime prevention. This often involves the use of various research technologies (e.g., geographic information systems and social network analysis) to analyze crime and public safety issues. Her current research examines the structure of illicit networks associated with criminal enterprise groups, transnational illicit markets, terrorism, and corporate interlock. Recent publications have appeared in the Journal of Research in Crime and Delinquency, Policing: An International Journal of Police Strategies and Management, Global Crime, Crime and Delinquency, Security Journal, Crime Patterns and Analysis, and Psychological Reports.

JANET ENRIQUEZ (janetenriquez@yahoo.com) holds an M.A. from California State University, San Bernardino and is a Research Associate with the Center for Criminal Justice Research (CCJR). Her research focus is on law enforcement in crime hotspots and evaluation of crime prevention initiatives. Recent journal publications appear in Crime and Delinquency and Policing: An International Journal of Police Strategies and Management. 